NBER WORKING PAPER SERIES

\title{
POLICY OPTIONS FOR FINANCING THE FUTURE HEALTH AND LONG-TERM CARE COSTS IN JAPAN
}

\author{
Tadashi Fukui \\ Yasushi Iwamoto \\ Working Paper 12427 \\ http://www.nber.org/papers/w12427
NATIONAL BUREAU OF ECONOMIC RESEARCH
1050 Massachusetts Avenue
Cambridge, MA 02138
August 2006

This paper is forthcoming in Fiscal Policy and Management in East Asia, edited by Takatoshi Ito and Andrew Rose. Earlier versions of this paper were presented at two meetings of the Economic and Social Research Institute (ESRI) International Collaboration Projects, February 15-16, 2005 and February 14-15, Tokyo; the 16th East Asian Seminar on Economics, June 23-25, 2005, Manila; and the Spring Meeting of the Japanese Economic Association, June 3-4, 2006, Fukushima. We would like to thank Henry Aaron, Raj Chetty, Olivia Mitchell, Epictetus Patalinghug, Motohiro Sato, and Wataru Suzuki and all the participants for their helpful comments at these meetings. Financial Support from the ESRI at the Japanese Cabinet Office is greatly appreciated. Iwamoto's Research is also financially supported by a Grant-in-aid for Scientific Research from the Ministry of Education. The views expressed herein are those of the author(s) and do not necessarily reflect the views of the National Bureau of Economic Research.

(C2006 by Tadashi Fukui and Yasushi Iwamoto. All rights reserved. Short sections of text, not to exceed two paragraphs, may be quoted without explicit permission provided that full credit, including (C notice, is given to the source. 
Policy Options for Financing the Future Health and Long-Term Care Costs in Japan

Tadashi Fukui and Yasushi Iwamoto

NBER Working Paper No. 12427

August 2006

JEL No. H55, I10

\section{$\underline{\text { ABSTRACT }}$}

As the Japanese population structure changes, health care and long-term care costs will steadily increase. The current style of financing (pay-as-you-go) will create a large increase in future burden of these costs. This paper studies an alternative policy that prefunds the social insurance benefits for the elderly.

During a transition process, the proposed scheme maintains a higher contribution rate in order to accumulate sufficient funds. Under our baseline scenario, the sum of the contribution rates toward health insurance and long-term care insurance increases from 5.06 percent of earnings to 12.41 percent of the same. The rate of increase in overall burdens, including taxes and subsidies, is 63 percent.

Our sensitivity analysis has shown that the quantitative implications of the increase in total burdens depend on social cost scenarios, the labor force, and the interest rate. However, labor force scenarios do not have a considerable impact on the rate of burden. As against this, the setting of social costs has a significant impact on the same.

Even under the most optimistic scenario, the rate of increase in total burden is 34 percent. Even though we cannot predict the exact amount of the necessary contribution rate that is capable enough to transfer the funded system, what we are sure of is that a significant increase in the contribution rate is inevitable.

Tadashi Fukui

Faculty of Economics

Kyoto Sangyo University

Motoyama, Kamigamo, Kita-ku

Kyoto 603-8555

JAPAN

fukuit@cc.kyoto-su.ac.jp

Yasushi Iwamoto

Graduate School of Economics

University of Tokyo

7-3-1, Hongo, Bunkyo-ku

Tokyo 113-0033

JAPAN

iwamoto@e.u-tokyo.ac.jp 


\section{Introduction}

The 2003 annual report on the Japanese Economy and Public Finance (released by the Japanese Cabinet Office) stated "the sustainability of the present fiscal and social security systems is uncertain and hence, an early commitment toward bold institutional reforms is required." The annual report listed for the first time social security reforms with regard to the aging population, and presented these reforms not in the form of a problem to be dealt with in the future but as an issue of urgent importance.

In the public pension reforms of 2004, Japan cut future pension benefits substantially. Since the ratio of the aggregate pension benefits to the national income (NI) is designed to be stable in the future, the financial problems associated with public pension have been resolved to some extent. Failure to reduce intergenerational inequality is a persistent problem in the public pension program; this is because the primary aim of the reforms was to reduce the pension benefits and contributions of future generations.

The expenditure incurred on health insurance and long-term care insurance is also expected to increase. It is not easy however to reduce these benefits as pension benefits because health care and long-term care services are essential for human welfare. Bradford and Max (1997) and Cutler and Sheiner (2000) have shown that an unfunded health insurance creates considerable intergenerational income redistribution. If these health insurance costs are financed using the current scheme (essentially, a pay-as-you-go system), a large increase in the future burden of these costs will become inevitable, thus creating an intergenerational imbalance of burden. One way of restoring intergenerational equity is for social insurance programs to prefund the expected increase in future costs. In this paper, we consider the effects of introducing a prefunding scheme on the intergenerational distribution of burdens. Based on the following three points, this paper gives new insights into the future financial problems of social insurance programs.

First, this paper examines both health care and long-term care programs. Feldstein (1999) proposed prefunding of the Medicare program, and Suzuki (2000) conducted a simulation study of the prefunding of the Japanese health insurance program. This paper also explores the concept of prefunding long-term care insurance. Annual spending on 
long-term care services is smaller than the expenditure incurred on health care services; however, long-term care costs are concentrated heavily on the aged population. Therefore, prefunding the cost associated with long-term care requires a large amount of saving. It is necessary to take into account both health and long-term care insurance in order to be able to comprehend the financial problems faced by social insurance programs in the future.

Our analysis of the intergenerational inequity of burdens is along the lines of the generational accounting pioneered by Auerbach, Gokhale, and Kotlikoff (1991). Since we have focused on the ways in which health and long-term care costs may be financed, the analytical framework adopted is somewhat different from that used in the generational accounting approach. We specify future policy variables and calculate the cost burdens with regard to the specified policy scenario. Our focus is confined only to health and long-term care insurances, while the generational accounting model considers a wider range of governmental programs. We have instead provided a detailed discussion of these programs.

Second, our simulation has a long time horizon until the fiscal year (FY) 2100, while the government has projected social security costs for health care and long-term care until FY 2025. Government projections with regard to social security costs were only until FY 2025 since the aging process was expected to reach its peak at this point with most baby boomers approaching the end of their lifetime. Due to a decline in fertility rates after the late 1970s, aging is now expected to continue beyond FY 2025; a much longer time horizon is required in order to examine the effects of a demographic change on social security costs.

Third, the validity of future projections is examined. The main alternative scenario here assumes that with the exception of population structure, all the present factors will be sustained in the future. This projection procedure is applied mechanically to the labor force, health care expenditure, and long-term care costs instead of constructing a sophisticated forecasting model. A virtue of the mechanical projection model is that relationships between the variables under consideration can be easily established. Comparing the projected values with the government's forecasts can clarify the manner in which projections are influenced by the government assumptions.

The organization of this paper is as follows. Section 2 describes the current 
problems in the budget of the Japanese social security programs. We point out that the growth of health and long-term care costs is the most serious problem for the sustainability of the government budget.

Section 3 focuses on the projections of labor force participation. The government projection is optimistic because it assumes that a greater number of women and the elderly will participate in the labor market. We provide an alternative projection in which increasing labor force participation is not expected. Although the estimated labor force depends on the assumptions of labor supply behavior, the trend decline in the total labor force will be significant in any scenario.

Section 4 focuses on health care expenditure and long-term care service costs. We project these costs until FY 2100 with regard to three scenarios. Even under the most optimistic scenario that assumes stagnation in the growth of per capita cost, the abovementioned costs to income will steadily increase until the 2060s.

Section 5 explains some policy simulations that deal with the financing of future health and long-term care costs until FY 2100. It is shown that the balanced budget operation of health and long-term care insurances will create a large inequity of burden across generations. Raising the premium immediately and prefunding rising future costs will help to equate the burden across generations. However, with regard to our baseline scenario, the total burden must be raised immediately by approximately 60 percent.

We present some concluding remarks in Section 6. 


\section{Long-term Projection of Social Security Benefits}

The Ministry of Health, Labor and Welfare (MHLW) occasionally publishes "Perspectives on the Benefits and Burdens of the Social Security System" (Shakai-hoshou no Kyufu to Futan no Mitooshi), which projects the benefits and burdens associated with public pension, health care, and social work, including long-term care. According to the projections made in May 2004 (we refer to it as MHLW 2004 projection hereafter), total social security benefits are expected to increase from 23.5 percent of the total NI at factor cost to 29 percent between FY 2004 and FY 2025 (see Table 1). ${ }^{1}$

Table 1: Projection of Social Security Benefits and Burdens

\begin{tabular}{lrrrr}
\hline \hline & \multicolumn{4}{c}{ Fiscal Year } \\
& 2004 & 2010 & 2015 & 2025 \\
& & & & \\
\hline & 23.5 & 25.4 & 27.0 & 29.0 \\
Social security benefits & 12.6 & 12.8 & 12.9 & 12.2 \\
Public pension & 7.1 & 8.2 & 9.2 & 11.2 \\
Health care & 3.8 & 4.3 & 4.7 & 5.7 \\
Welfare, etc. & 1.4 & 2.2 & 2.7 & 3.6 \\
$\quad$ Long-term care & 21.3 & 24.2 & 26.6 & 29.5 \\
Social security burdens & 14.2 & 15.5 & 16.7 & 18.3 \\
Social insurance premium & 7.1 & 8.7 & 9.6 & 11.2 \\
Government subsidies & & & & \\
& & & &
\end{tabular}

Note) Numbers indicate percentages of NI at factor cost.

Source) Perspectives on the Benefits and Burdens of Social Security System (May 2004, Ministry of Health, Labor and Welfare).

However, future trends in these benefits vary with social security programs. Public pension benefits will not increase and will actually become slightly lower in FY 2025 as compared to their current levels. This stabilization of future pension benefits

1 The ratio of total security benefits to NI at factor cost indicates an unnecessary fluctuation when the VAT tax rate changes. The Japanese government had begun to use the ratio of total security benefits to NI at factor cost long before the introduction of VAT. In this paper, however, we shall focus on the ratio of these benefits to GDP instead. 
was achieved by the pension reform of 2004. Prior to this reform, the contribution rate for private employees toward the pension program was planned to increase gradually from 13.58 percent of total earnings to 23.1 percent of the same in FY 2020. Since this figure appeared to be unacceptable, controlling the contribution rate became the primary focus of this reform. The final contribution rate was reduced to 18.3 percent of total earnings, and a significant reduction in benefits for the future was implemented. However, this reform does not resolve all of the major problems. As explained by Maekawa (2004), since benefits are gradually reduced, the reform fails to correct the inequity in net benefits among generations. An immediate reduction in benefits accompanied by an increase in the contribution rate is necessary to reduce the intergenerational inequity.

An emerging component of social costs is the benefits of health insurance and long-term care insurance. Health care benefit as a fraction of NI will increase by 4.1 percentage points until FY 2025, whereas the long-term care benefit will grow by 2.2 percentage points during the same period. The big question that needs to be answered by the policy makers is: How to finance these costs?

If health and long-term care insurances are operated by the pay-as-you-go system, the cost burden on workers will steadily increase, thus creating an intergenerational imbalance of burdens. Prefunding future social security costs will help to reduce this imbalance by forcing the present generations to pay more, thereby reducing the extra burden on future generations. The financial condition of a prefunding system relies on future economic variables such as the interest rate, wage growth rate, and technological change in medicine. Since the reliability of a future projection is a crucial factor in determining the success of a prefunding schemes, we shall examine how a prefunding system is affected by the future conditions of the Japanese economy. 


\section{Economic Growth and the Labor Force}

In this section and the succeeding one, we shall discuss the properties of governmental projections and provide our alternative projections on the labor force, economic growth, health care costs, and long-term care costs. This section focuses on variables that determine income.

The publication "Perspectives on the Benefits and Burdens of Social Security" does not rely on a general equilibrium model of the economy. It assumes the growth rate of real national income to be the sum of the growth rates of wage and labor force. This framework can be justified in the following situation. A production function is homogeneous of degree one with capital $K$ and labor $L$. This function witnesses a labor-augmenting technological progress. It is represented as

$$
Y=F(K, A L)
$$

Here, $Y$ and $A$ represent the output and efficiency, respectively. Differentiating (1) with respect to time yields

$$
\frac{\dot{Y}}{Y}=\frac{F_{K} K}{Y}\left(\frac{\dot{K}}{K}-\frac{\dot{A}}{A}-\frac{\dot{L}}{L}\right)+\frac{\dot{A}}{A}+\frac{\dot{L}}{L} .
$$

When the growth rates of capital and efficiency unit of labor are the same, the first term in the RHS of (2) becomes zero. The economic growth rate then equals the sum of the growth rate of labor-augmenting technological change (the wage growth rate) and the growth rate of labor input.

The MHLW 2004 projection assumes the growth rate of labor input to be 0.1 percent until FY 2008, -0.2 percent in FY 2009 and FY 2010, and -0.5 percent from FY 2011 onwards. The labor force in FY 2025 will be 61.58 million, which is 7.24 percent smaller than its level in 2004. This framework is based on a detailed projection of the labor force titled "A Forecast of Labor Force Participation Rates" (Rodoryokuritsu no Mitooshi), which was compiled by the Employment Security Bureau of MHLW in May 2002 (We shall refer to it as the MHLW 2002 labor force projection). The lower section of Table 2 indicates that the MHLW 2002 labor force projection forecasts an increase in the labor force participation rates of the elderly and women. The upper section of Table 
2 however, indicates the labor force calculated by multiplying the labor force participation rates as reported by the Employment Security Bureau and the official population projections (medium variant) for each age group. The calculated labor force in 2025 is 62.97 million, which is slightly greater than those estimated by the MHLW 2004 projection. The initial point of the MHLW 2002 labor force projection was 2000, when the total labor force was 67.66 million. Due to the decline in the labor force to 66.42 million in 2004, The MHLW 2004 projection starts with a smaller initial point and adopts a similar growth rate, thus estimating a smaller labor force in the future.

Table 2: The Projection of the Labor Force by MHLW

\begin{tabular}{|c|c|c|c|c|}
\hline \multirow[b]{2}{*}{ Year } & \multicolumn{2}{|c|}{ Male } & \multicolumn{2}{|c|}{ Female } \\
\hline & 2000 & 2025 & 2000 & 2025 \\
\hline $\begin{array}{l}\text { Labor force } \\
\text { (thousands) }\end{array}$ & 40,140 & 36,310 & 27,520 & 26,655 \\
\hline $\begin{array}{l}\text { Labor force } \\
\text { Rates by age } \\
\text { (percent) }\end{array}$ & $\begin{array}{l}\text { cipation } \\
\text { up }\end{array}$ & & & \\
\hline $15-19$ & 18.4 & 20.1 & 16.6 & 17.8 \\
\hline $20-24$ & 72.7 & 77.6 & 72.7 & 73.7 \\
\hline $25-29$ & 95.8 & 95.9 & 69.9 & 75.3 \\
\hline $30-34$ & 97.7 & 97.6 & 57.1 & 65.0 \\
\hline $35-39$ & 97.8 & 97.8 & 61.4 & 67.4 \\
\hline $40-44$ & 97.7 & 97.8 & 69.3 & 75.2 \\
\hline $45-49$ & 97.3 & 97.5 & 71.8 & 77.0 \\
\hline $50-54$ & 96.7 & 96.9 & 68.2 & 73.5 \\
\hline $55-59$ & 94.2 & 94.4 & 58.7 & 67.5 \\
\hline $60-64$ & 72.6 & 85.0 & 39.5 & 60.5 \\
\hline $65-$ & 34.1 & 29.5 & 14.4 & 13.0 \\
\hline
\end{tabular}

Note: The 2025 labor force is calculated by multiplying the projected population (medium variant) reported in the Population Projections for Japan: 2001-2050 (January 2002, National Institute of Population and Social Security Research) by the labor force participation rates by age groups.

Source: The 2025 labor force: the Perspective on the Labor Force Participation Rate (July 2002, the Employment Security Bureau, Ministry of Health, Labor and Welfare) and the 2000 labor force and labor force participation rate: the Labor Force Survey (the Statistics Bureau, Ministry of Internal Affairs and Communications). 
While the government projection assumes an increase in the labor force participation, we are apprehensive of this increase not being realized. To examine the impact of projecting a future labor supply optimistically, we considered an alternative scenario. $^{2}$ We used the labor force participation rates by age from the 2000 Population Census and the future population estimates from "The Population Projections for Japan: 2001-2050" (January 2001, National Institute of Population and Social Security Research). The Population Census records the labor force participation rates of individuals up to 84 years of age (individuals aged 85 years and above are categorized as one age group). We rescaled the labor force participation rates of each group in such a manner that our estimates of the total labor force in 2000 were in concordance with the values reported in 2004 by the Labor Force Survey. ${ }^{3}$

Table 3 shows our mechanical projection. From 2004 to 2005, the labor force will decrease by 8 million to a level of 58.39 million people. A decrease in the labor force will continue after 2025 and every decade will witness a labor force loss of more than five million people. In 2050, a total labor force of 44.69 million people will be available. The rate of change in the total labor force with regard to its value in 2004 is 32.7 percent. When a population projection is based on a low variant, the projected number becomes more pessimistic. In 2050, the rate of change in the total labor force with regard to its value in 2004 is 38 percent. Since the effects of a low birth rate appear only after newborn generations begin to work, the labor force in 2025 does not show considerable variations.

2 Iwamoto (1998) analyzed existing studies on labor force and also projected the labor force until 2020. His mechanical projection assumes that the present labor force participation rates by age groups will be sustained in the future and that the structure of future populations will change. His estimates are not very different from preceding estimates made in academic studies that also incorporated behavioral changes. This can be attributed to the fact that there is no scope for drastic changes in the labor force participation rates of working-age populations. In addition, although the trend regarding birth rates in the future is uncertain, future population can be predicted with considerable surety.

3 The Population Census recorded the labor force in 2000 to be 66.1 million. According to the Labor Force Survey, it was 67.66 million. 
Table 3: Mechanical Projection of the Labor Force

thousand person)

\begin{tabular}{|c|c|c|c|c|c|c|c|c|c|c|c|}
\hline Year & 2004 & 2010 & 2020 & bor Force & 2030 & 2040 & 2050 & $\begin{array}{l}\text { the Change } \\
\text { from } 2004 \\
\text { to } 2025\end{array}$ & $\begin{array}{l}\text { the Rate of } \\
\text { Change } \\
\text { (percent) }\end{array}$ & $\begin{array}{l}\text { the Change } \\
\text { from } 2004 \\
\text { to } 2050\end{array}$ & $\begin{array}{l}\text { the Rate of } \\
\text { Change } \\
\text { (percent) }\end{array}$ \\
\hline \multicolumn{12}{|c|}{ Medium variant (baseline) } \\
\hline Both sexes & 66,390 & 64,432 & 60,353 & 58,393 & 56,000 & 50,128 & 44,687 & $-7,997$ & -12.0 & $-21,703$ & -32.7 \\
\hline Males & 39,040 & 38,059 & 35,580 & 34,449 & 33,134 & 29,783 & 26,550 & $-4,591$ & -11.8 & $-12,490$ & -32.0 \\
\hline Females & 27,350 & 26,373 & 24,774 & 23,945 & 22,866 & 20,345 & 18,138 & $-3,405$ & -12.5 & $-9,212$ & -33.7 \\
\hline \multicolumn{12}{|l|}{ Low variant } \\
\hline Both sexes & 66,390 & 64,432 & 60,331 & 58,172 & 55,306 & 48,080 & 41,190 & $-8,218$ & -12.4 & $-25,200$ & -38.0 \\
\hline Males & 39,040 & 38,059 & 35,568 & 34,336 & 32,769 & 28,626 & 24,520 & $-4,704$ & -12.1 & $-14,520$ & -37.2 \\
\hline Females & 27,350 & 26,373 & 24,763 & 23,837 & 22,537 & 19,454 & 16,670 & $-3,513$ & -12.8 & $-10,680$ & -39.0 \\
\hline
\end{tabular}

Note: Author's calculation. The labor force participation rates by age group are from the 2000 Population Census, Ministry of Internal Affairs and Communications, and the figures for future populations are from the Population Projections for Japan: 2001-2050 (January 2002, National Institute of Population and Social Security Research). The future labor force is calculated by assuming that the labor force participation rates for 2000 will be sustained. 
The MHLW 2004 projection regarded the labor force as a labor input. Since the efficiency of labor varies with age, the overall values of labor force and labor input may fluctuate differently. However, the procedure followed in the MHLW 2004 projection can be refined. We estimated an efficiency unit of labor implied by the two MHLW projections, assuming that efficiency is directly proportional to wage. The age-wage profile by age group and sex was collected from the published cross-tables of the 2003 Basic Survey on Wage Structure (Chingin Kozo Kihon Chosa, MHLW). For each age the efficiency unit of labor input is calculated as the product of the total wage per worker and the projected labor force. We rescaled the aggregated efficiency unit of labor in 2004 so that it equalled the total labor force in that year. We considered three scenarios: our mechanical projection (pessimistic), the MHLW 2004 projection (optimistic), and the MHLW 2002 projection (more optimistic).

Figure 1 depicts the three scenarios regarding labor input. According to our abovementioned normalization, the MHLW 2002 labor force projection estimated the labor input in 2025 to be 63.02 million. The 2004 counterpart of our mechanical projection is estimated to be 59.03 million. The MHLW 2004 projection underlying the social security cost projection lies between these two values. While the difference between these projections is significant, all of them project a further decline in the value of labor input after 2025. In 2100, the value of labor input is estimated to be 30.08 million in the most optimistic case as against 28.08 million in the most pessimistic one. The bottom line is that even in the most optimistic scenario, the large decline in the availability of labor force will be unavoidable. 
Figure 1: Comparison of Three Labor Input Projections

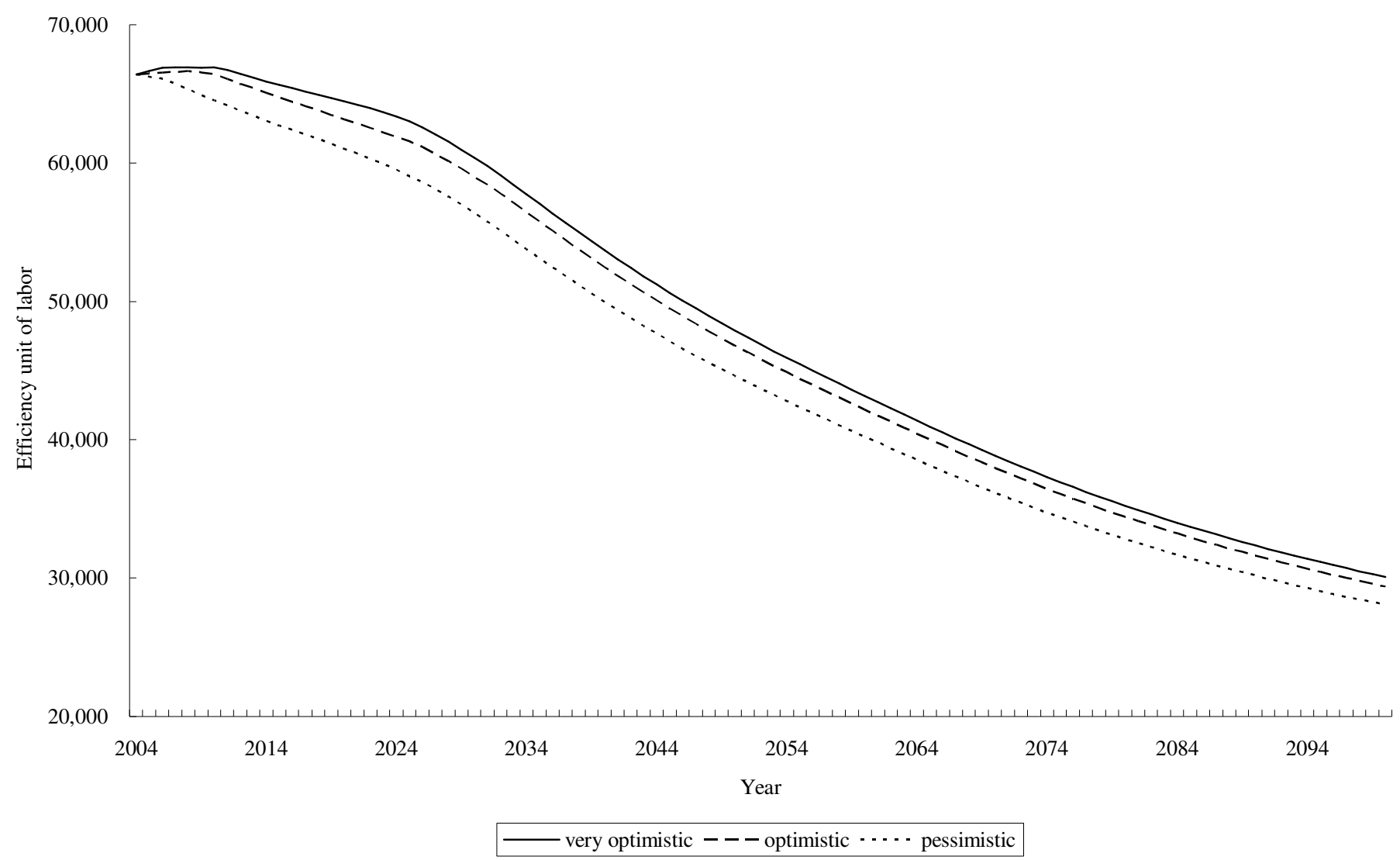




\section{Long-term Projections of Health and Long-term Care Benefits}

The MHLW projection assumes that the costs incurred by health care and long-term care will grow more rapidly as compared to income. If our mechanical projection procedure is applied to both these costs, the estimates will be smaller than those estimated by official projections. To clarify the meaning of the official projections,

this section describes a sensitivity analysis employing alternative settings for the key variables. Combining the two scenarios of health and long-term care costs with the three projection scenarios of labor forces, we apply six cases of projections. The following two subsections describe a procedure used for projecting the two costs. We then present the results obtained for the sensitivity analysis.

\subsection{Health Care Cost}

Table 4 compares five recent projections about health care and long-term care costs. Since projections in different years assume different inflation rates, comparing nominal variables is misleading. When we look at the ratios of social security benefits to NI, projected health expenditures differ mildly. The real growth of health care costs appears to be more stable than the nominal growth of the same. 
Table 4: Perspectives on Health Care and Long-term Care Costs Reported by the Ministry of Health, Labor and Welfare

(trillion yen)

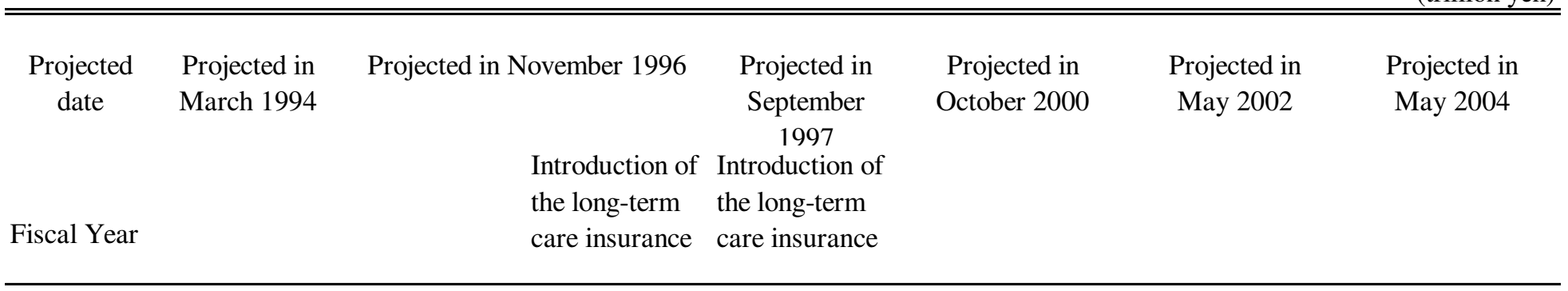

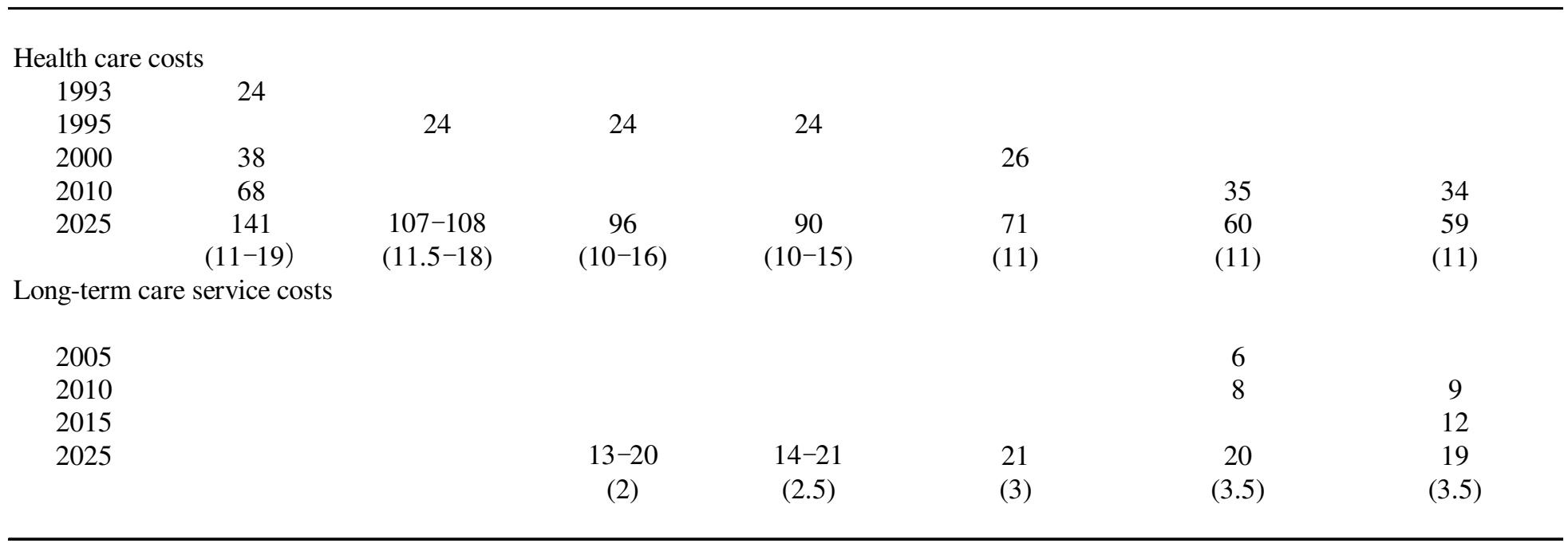

Note: Numbers represent benefits of each type of social insurance. The numbers in parenthesis represent the ratio of social insurance benefits to NI at factor cost.

Source: Welfare Vision for the 21st Century (May 1994, Ministry of Health and Welfare) and various issues of Perspectives on the Benefits and Burdens of the Social Security System (Ministry of Health, Labor and Welfare). 
Future health expenditures are projected by extrapolating the most recent actual values of nominal health expenditure; these do not correspond with the values of inflation rate and economic growth rate. For example, the May 2004 projection assumes that the per capita nominal health care cost for the nonelderly (individuals under the age of 69) will grow at 2.1 percent and that for the elderly aged 70 and above will grow at 3.2 percent. These growth rates are based on the historical averages recorded during 1995 and 1999. ${ }^{4}$ The extrapolation of nominal health expenditure without taking into account the effects of inflation can be problematic from the viewpoint of economic theory. Economists generally make projections based on real values, and the methodologies adopted by them belong to a family of mechanical projections. Iwamoto (2004) analyzed several projections made in existing studies such as Ogura and Irifune (1990), Ogura (1994), Niki (1995), Iwamoto, Takeshita, and Bessho (1997), Nishimura (1997), and Tokita et al. (1997). He concluded that in the following 30 years, the national health expenditure would increase by about 1.4 times compared to its level in 2000. Our mechanical projection follows a method established by existing studies and assumes that per capita health expenditure by age group reported in the National Medical Expenditure (MHLW, shown in Table 5) will be sustained in the future. For the future population data, we use the medium variant of the official projection.

Although the above projection assumes no real growth of health care cost, it can be easily extended to cases in which the health care cost grows. When the economy grows, we focus on the ratio of health care cost to income. When the health care cost and income grow at the same rate, the ratio will not change. In such a scenario, our mechanical projection estimates can be considered as this ratio. In the alternative framework described in the next section, we will concern ourselves only with the difference in growth rates between costs and income and not with the absolute levels of each growth rate.

4 The MHLW provides an estimation of the growth rate in medical expenditure after adjusting for the effects of population aging since 1980. Overall, the per capita medical expenditure had grown less than per capita GDP; however, this correspondence was reversed during the1990s. 
Table 5: Expenditures on Health Care and Long-Term Care per Capita by Age Group (2004 Fiscal Year)

(yen)

\begin{tabular}{|c|c|c|}
\hline Age Group & Health care & $\begin{array}{l}\text { Long-term } \\
\text { care }\end{array}$ \\
\hline $0-4$ & 158,900 & \\
\hline $5-9$ & 92,100 & \\
\hline $10-14$ & 66,700 & \\
\hline $15-19$ & 58,100 & \\
\hline $20-24$ & 71,200 & \\
\hline $25-29$ & 85,600 & \\
\hline $30-34$ & 97,500 & \\
\hline $35-39$ & 103,000 & \\
\hline $40-44$ & 119,100 & $5,700 \quad(40-64)$ \\
\hline $45-49$ & 149,900 & \\
\hline $50-54$ & 199,200 & \\
\hline $55-59$ & 245,000 & \\
\hline $60-64$ & 323,100 & \\
\hline $65-69$ & 433,400 & 43,800 \\
\hline $70-74$ & 564,800 & 97,000 \\
\hline $75-79$ & $749,400 \quad\left(75^{-}\right)$ & 203,200 \\
\hline $80-84$ & & 429,400 \\
\hline $85-89$ & & 799,900 \\
\hline $90-94$ & & $1,236,100$ \\
\hline $95-$ & & $1,786,500$ \\
\hline
\end{tabular}

Note: The values are the sum of benefits from insurers and copayments by patients.

Health care expenditure is calculated by proportionally adjusting the FY 2002 value reported in the National Medical Expenditure (Ministry of Health, Labor and Welfare) so that the national aggregate matches the health care expenditure reported by MEDIAS; this system totals the costs of services covered by public health insurance. The National Medical Expenditure categorizes individuals who are 75 years of age and above as one age group.

Long-term care expenditure: the values are calculated by multiplying the actual costs of services covered by long-term care insurance in October 2004 as reported in the Monthly Report of Long-term Care Benefits (Ministry of Health, Labor and Welfare) by 12 . Individuals who are 40 years of age and above can be the recipients of long-term care insurance. The Report categorizes individuals between 40 and 60 years of age as one age group. 
Since we intend to frame our mechanical projection in such a way that it is comparable with the MHLW 2004 projection, the data with regard to age group were converted so that they were in concordance with the income level of FY 2004. First, per capita health care cost by age group was proportionally adjusted so that the national aggregate of the same matches the figures reported in the Medical Information Analysis System (MEDIAS), which reports the health care costs paid by public health insurance. The national aggregate of health care costs was calculated as the product of population and per capita cost by age group. The rescaled age-cost profile was used to project future health care costs.

Further, we decomposed the total cost toward social insurance payment and out-of-pocket expenses. Unfortunately, MEDIAS does not provide this decomposition. We obtained the figures for social security payment from the National Medical Expenditure survey (Kokumin Iryohi). ${ }^{5}$ While allocating social insurance payment across generations, we used the statutory coinsurance rates of 2004 and assumed that they will be sustained in the future. Since April 2003, the coinsurance rate for the age group 0-2 years has been 20 percent, whereas for the age group 3-69, it has been 30 percent. For individuals aged 70 years and above, the rate in principle has been 10 percent (a rate of 20 percent is applied to high-income earners). Due to the lack of available data, we assume that a rate of 10 percent is applied to all individuals aged 70 and above. However, the actual out-of-pocket payments are less than the statutory coinsurance rate because of stop-loss rules and other schemes to reduce out-of-pocket expenses. We proportionally scaled the statutory coinsurance rates so that the sum of the estimated social insurance payments matched the aggregate values reported by MEDIAS in 2004.

Since the available data on health expenditure does not separately report the expenditure incurred for the age groups $0-2$ and 3-4, we assumed that the health expenditure per capita will be uniform in these age groups; we then calculated the

5 The National Medical Expenditure (NME) lags one year behind MEDIAS in the release of data. We first estimated the $2004 \mathrm{NME}$ data by multiplying the growth rate of a comparable MEDIAS variable between 2003 and 2004 with the 2003 NME data. Since out-of-pocket expenses for NME also include payments of medical treatments that are not covered by the social security programs, we estimated the out-of-pocket payments as a residual of the overall payments. 
average coinsurance rate. Since actual costs are concentrated on newborn babies, this procedure may slightly overestimate the true social security payment value. However, at the same time, many municipal governments offer extra benefits toward the health expenditure of infants from their general budget. Since we do not incorporate these subsidies into our estimation process, it results in an underestimation of the social security benefits granted to these age groups. However, the overall impact of these subsidies on our estimation bias is ambiguous.

We then reproduced the MHLW 2004 projection of the future health insurance benefits. The MHLW 2004 projection assumes that the nominal wage growth rate is 2.1 percent per annum. Therefore, per capita health care costs for the nonelderly will grow simultaneously with the growth rate of wage. As against this, the growth rate of per capita costs for the elderly will exceed that for wage by 1.1 percentage points. The projection with regard to the nonelderly is the same as our mechanical projection. For costs beyond 2025, we need to first specify the growth rate of wage for the same. If the growth rate of health care costs continuously exceeds that of wage, it will ultimately exhaust all the resources available to consumers. We thus need to assume that the growth in health care costs will cease sometime in the future. Hence, we consider two cases in which a faster growth in health care costs will eventually stop in FY 2025 or FY 2100. In the former case, the per capita health care cost for the elderly is 5.56 times greater than that for the nonelderly. The counterpart in FY2004 is 4.3. In the latter case, an extreme increase occurs in the growth of health care cost for the elderly; the ratio in FY2100 will be 13.09 .

As a measure of financial burden, we focus on the ratio of social security benefits to the compensation of employees and the mixed income in terms of national accounts. The denominator of the ratio is assumed to be proportional to the amount of labor input. Changes in future health care costs can be described by the following three scenarios: the per capita health care cost for the elderly will (1) grow at the same rate as that of wage growth (optimistic), (2) will exceed the wage growth rate by 1.1 percentage points until FY 2025 (pessimistic), or (3) will exceed the wage growth rate by 1.1 percentage points until FY 2100 (very pessimistic). Combining these three scenarios with future changes in labor input yields nine different cases of future projection. The upper section of Table 6 presents these ratios. 
Table 6: Projection of the ratio of Health and Long-term Care Costs to Labor Input

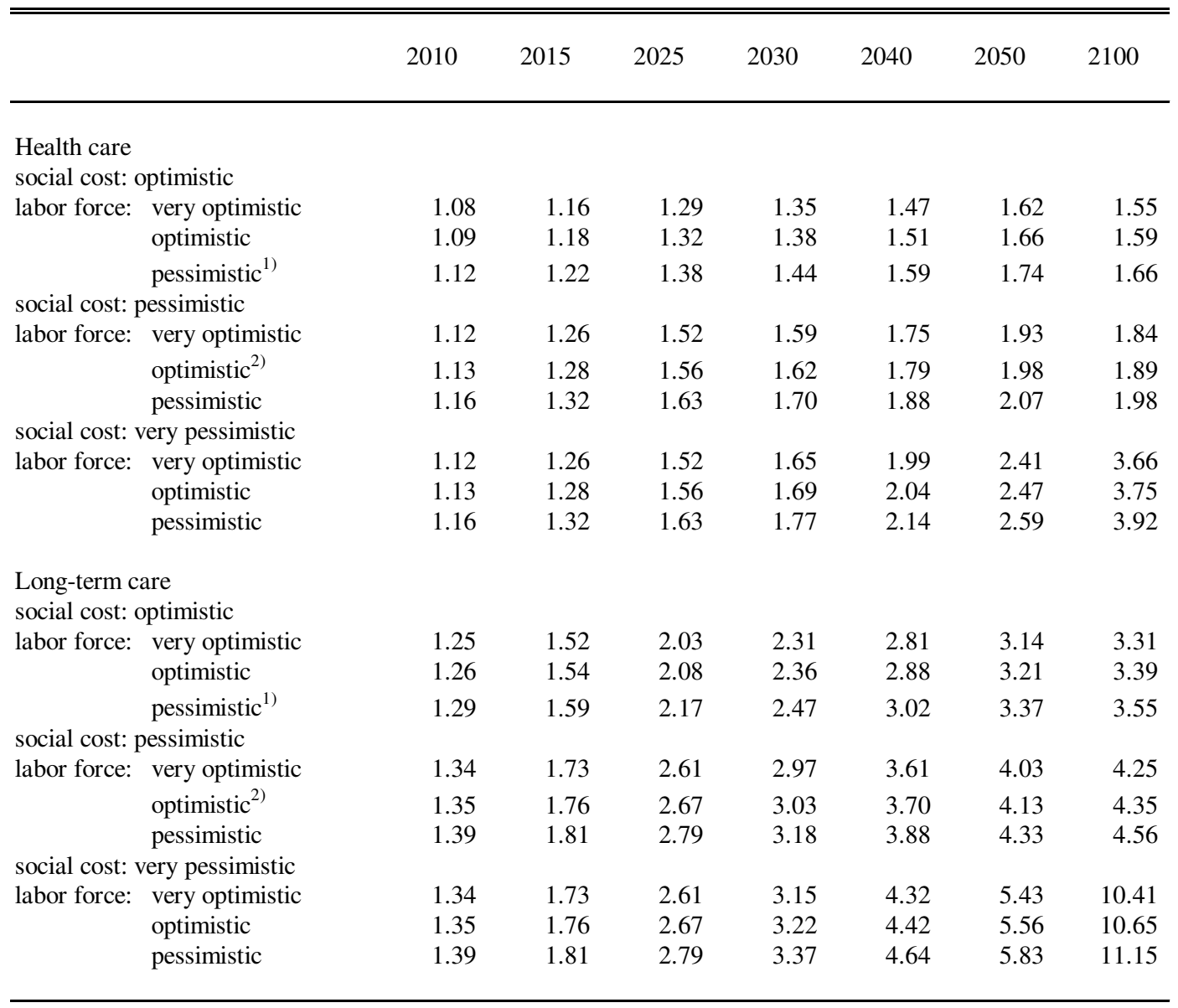

Notes: Numbers represent the ratio of health care costs and long-term care costs to labor input (FY $2004=1$ ). 1) Mechanical projection. The future labor force participation rate and per capita social cost by age group will be constant.

2) A projection that replicates the MHLW 2004 projection, which is reported in Table 1.

Source: Author's calculation.

The MHLW 2004 projection indicates that the ratio of health expenditure to labor input in FY 2025 will exceed its value in FY 2004 by 1.58. This scenario was reproduced in our social cost pessimistic and labor force optimistic scenarios; this indicates that the ratio will grow by a factor of 1.56 between FY 2004 and FY 2025. On the other hand, same ratio under the mechanical projection will grow by a factor of 1.38 during the same period. Therefore, the MHLW 2004 projection is more pessimistic with regard to a future increase in health expenditure as compared to our mechanical projection. However, the most pessimistic scenario is a combination of an extremely 
pessimistic projection of health care costs coupled with a mechanical projection of the labor force in the future. In this case, the ratio of health expenditure to labor input in FY 2025 will exceed its value in FY 2004 by 1.63.

A noticeable point is that this ratio will keep increasing, and its value in 2050 under the setting employed by the governmental projection will be 1.98 times greater than its value in FY 2004. In other words, FY 2025 cannot be regarded as the terminal point for examining the sustainability of the health insurance system. ${ }^{6}$

\subsection{Long-term care costs}

The government anticipates that long-term care costs will grow more rapidly as compared to health care costs. According to the MHLW 2004 projection given in Table 4, the long-term care insurance benefits in FY 2025 (the ratio of long-term care benefits to NI) will be 2.7 times greater than its value in FY 2004. The growth rate of per capita long-term care costs is set to be higher than the wage growth rate although detailed assumptions have not been explicitly documented.

Municipal governments prepare three-year business plans for long-term care insurance. Prior to the first revision that was made in FY 2003, The Projection of Demand for Long-term Care (Kaigo Sahbisuryou tou no Mitooshi, June 2002) was provided by the MHLW; it expected an increased demand for long-term care in the following five years. For example, the provisional nationwide sum of the usage of home-visit services will increase by 39.3 percent from FY 2003 (142,194 visits) to FY

${ }^{6}$ We should note that our projections may be biased in an upward direction because they do not take into account the effects of aging on terminal care expenses. In Japan, Ohkusa (2002) and Suzuki and Suzuki (2003) provided a modified projection that took into account this aspect. Since terminal care expenses for the more aged tend to decrease, a longer longevity will increase the average age of death; hence, future health expenditure by age group is expected to be lower than its present level. Taking this effect into consideration, the abovementioned studies pointed out that the MHLW 2004 projection overestimated the future health expenditure. Suzuki and Suzuki (2003) reported this overestimation amounted to approximately 4.4 percent of the total health expenditures for the elderly. On the other hand, Ohkusa (2002) concluded that the overestimation reached a level of approximately 15 to 30 percent of the total health expenditures. The divergence in their estimates is quite large because data limitations made it difficult to separate the medical expenditures of the survivors from the medical expenses incurred by those who died. 
2007 (198,033 visits). ${ }^{7}$ The projection however, did not provide the total amount of long-term care costs. We calculated the sum of these provisions weighted by their actual costs in FY 2003 and the resulting growth during FY 2003-2007 that amounted to 26.4 percent.

We projected the future long-term care insurance benefits by adopting a methodology similar to that used for the projections of health insurance. ${ }^{8}$ At the time of writing this paper, most recent data for annual spending by age group was available for FY 2002; hence, we estimated annual spending on the basis of monthly data. The long-term care expenditure by age group in October 2004 was calculated from the Monthly Report of Long-term Care Benefits Survey (Kaigo Kyufuhi Jittai Chosa Geppo) conducted by the MHLW. ${ }^{9}$ We then calculated annual spending by multiplying the monthly data with 12 and reported it in the right column of Table 5. The future long-term care expenditure was then projected under the following three settings. The first one (optimistic) assumed that the age-expenditure profile would not change and that only the population structure would change. We then decomposed the total spending into social security benefits and out-of-pocket expenses by assuming that the ratio of out-of-pocket payments to total costs in FY $2002\left(8.99\right.$ percent $\left.^{10}\right)$ would be sustained.

We then analyzed the following three scenarios of long-term care costs: (1) the per capita cost of each age group will grow at the wage growth rate (optimistic); (2) until 2025, the rate of growth in per capita cost will exceed the wage growth rate by 1.2 percentage points and as a result, the total cost per income well approximated the MHLW 2004 projection (pessimistic); and (3) until 2100, the per capita cost will grow

7 This projection presumed that the number of individuals certified as requiring care in FY 2003 was 3,279,000; however, the actual number of these certified individuals was 2,983,000 at the end of FY 2003.

8 Mitchell, Pigott, and Shimizutani (2004), Shimizutani and Noguchi (2004), and Suzuki (2002) are involved in projecting the future long-term care costs.

9 The data source does not directly report cost by age group. The available cross tables indicate (1) the cost by the severity of disability and (2) the total number of beneficiaries by the severity of disability and age group. Assuming that the long-term care cost of each level of disability was the same across all age groups that were considered, we estimated the total cost by age group by using these two cross tables.

${ }^{10}$ It is slightly lower than the statutory coinsurance rate (10 percent) because there are some measures that lighten the burden of out-of-pocket payments. 
at a rate that exceeds the wage growth rate by 1.2 percentage points (very pessimistic). The properties of these settings parallel those applied for health care costs. Combining these settings with three labor force projections yields nine scenarios. The resulting ratios are presented in the lower section of Table 6.

The rate of growth from FY 2004 to FY 2025 is projected to lie between 2.03 and 2.79. According to the governmental projection, it is estimated to be 2.67 , which is relatively pessimistic. If the per capita long-term care cost grows at the existing wage growth rate, the rate of growth is estimated to range between 2.03 and 2.17 depending on the labor force scenario. 


\section{Simulation of Health Care and Long-term Care Insurance Policies}

\subsection{Procedures of the simulation}

This section deals with the simulation of policies that finance future health and long-term care insurance benefits, the projections of which were described in the previous section. This section focuses on the effect of these policies on fiscal balances and burdens across generations.

Since we regard the benefits derived from these insurances as necessary services when a person becomes sick or disabled, it is not very meaningful to discuss the intergenerational distribution of these benefits. Hence, our simulation focuses only on the financing of these benefits.

From October 2007, half of the benefits derived from the health insurance of those aged 75 and above will be financed with government subsidies that are in turn financed by general tax revenues. Until October 2002, only 30 percent of these benefits for those aged 70 and above were financed with government subsidies. From 2002 to 2007, a transition process gradually raised the eligible age and the share of government subsidies. Half of the long-term care insurance benefit is financed with government subsidies. The other major subsidies granted by the government are 50 percent of the benefits of National Health Insurance schemes (Kokuho) and 13 percent of the Government-managed Health Insurance for Employees (Seikan Kenpo).

We assume that social insurance premiums and taxes for social insurance benefits are paid from the same income base, which is the compensation of employees and the mixed income in terms of national accounts. For simplicity, we further assume that these incomes will grow at the same rate as GDP (and labor input) after FY 2004 and that there are no administrative costs involved in the implementation of such social insurance programs. ${ }^{11}$

The initial and terminal years of the simulation process are set as FY 2004 and FY 2100 , respectively, because the population projection carried out by the National Institute of Population and Social Security Research is available only within these

11 For instance, the administrative cost involved with the implementation of Society-Managed Health Insurance for Employees is about 0.4 percent of the total benefits derived from such programs during FY 2001. 
periods.

We consider the following two policies

Policy A: A balanced budget operation in which the benefits during each year are financed by the taxes and insurance premiums of the corresponding year

Policy B: An attempt to reduce the intergenerational inequity of burdens by prefunding future social insurance payments for the elderly (details will be described in Section 5.3)

\subsection{Balanced budget}

We define burden rate as the ratio of burdens (the sum of insurance premiums and government subsidies financed by taxes) to 90 percent of the sum of compensation of employees and the mixed income. We aimed to calibrate the statutory premium rate by rescaling the sum of the compensation received by the employees and the mixed income. The health insurance premium (including government subsidies for the nonelderly and excluding those reserved for the elderly) for the initial year, i.e., FY 2004, is calculated to be 8.21 percent. The actual health insurance premium for the enrollees of the Government-Managed Health Insurance for Employees is calculated to be 8.2 percent. Since the enrollees of the Government-managed Health Insurance for Employees are employed with small companies, their average salary is lower than that of all the workers. Since government subsidies aim to offset the earnings difference, we tried to calibrate the statutory insurance premium. With regard to long-term care insurance, the simulated premium rate for FY 2004 is 1.11 percent; this matches the actual insurance premium paid by the enrollees of the Government-managed Health Insurance for Employees. Under the balanced budget, the burden is equal to social insurance benefits (excluding out-of-pocket payment). Therefore, we calculated the ratio of benefits to incomes.

Figure 2 presents the burden rates associated with health care, long-term care, and a total of both of them when Policy A is implemented under the governmental projection (social cost-pessimistic and labor force-optimistic). The burden rate for health care continues to increase until FY 2059 when it touches 19.94 percent. As against this, the burden rate for long-term care will touch 10.97 percent in FY 2066. 
Although the paths followed by these two burden rates appear to be parallel to each other in Figure 2, we must however, note that the absolute level of long-term care costs is low. The burden rate for long-term care grows much more rapidly than that for health care because compared to health care benefits, long-term care benefits are concentrated to a greater extent on the aged population. For the same reason, a peak representing the burden rate for long-term care will follow a peak of the burden rate for health care. The total burden rate of both the insurances reaches a peak that is 30.65 percent in FY 2064. The ratio of total burden to GDP then amounts to 15.63 percent in the same year.

Figure 3 presents the lifetime burden rate of each generation under the governmental projection. It is defined as the ratio of lifetime burden to lifetime income. The lifetime variable is the sum of the present discounted values of the reported annual numbers during the period between the initial and the terminal points of the simulation process. Therefore, the burden rate is the prospective lifetime burden for the generation born in 2001 or earlier. To estimate lifetime income, we adopted the age-wage profile, which was used to calculate the labor input in Section 3. The interest rate is assumed to be 1 percentage point higher than the wage growth rate.

The horizontal axis of Figure 3 represents the birth year of each generation. The curve representing the lifetime burden rates are not smooth for early generations, possibly because our prospective calculation covers only a short period for these generations. Figure 3 indicates that a balanced budget system will impose heavier burdens on the younger generations. The inequality of burdens is particularly severe for the current working-age generation. The lifetime burden rate for those who were born in 2001 is estimated to be 26.2 percent while the same for those born in 1945 is 14.8 percent. 
Figure 2: The Burden Rates under Policy A (Balanced Budget)

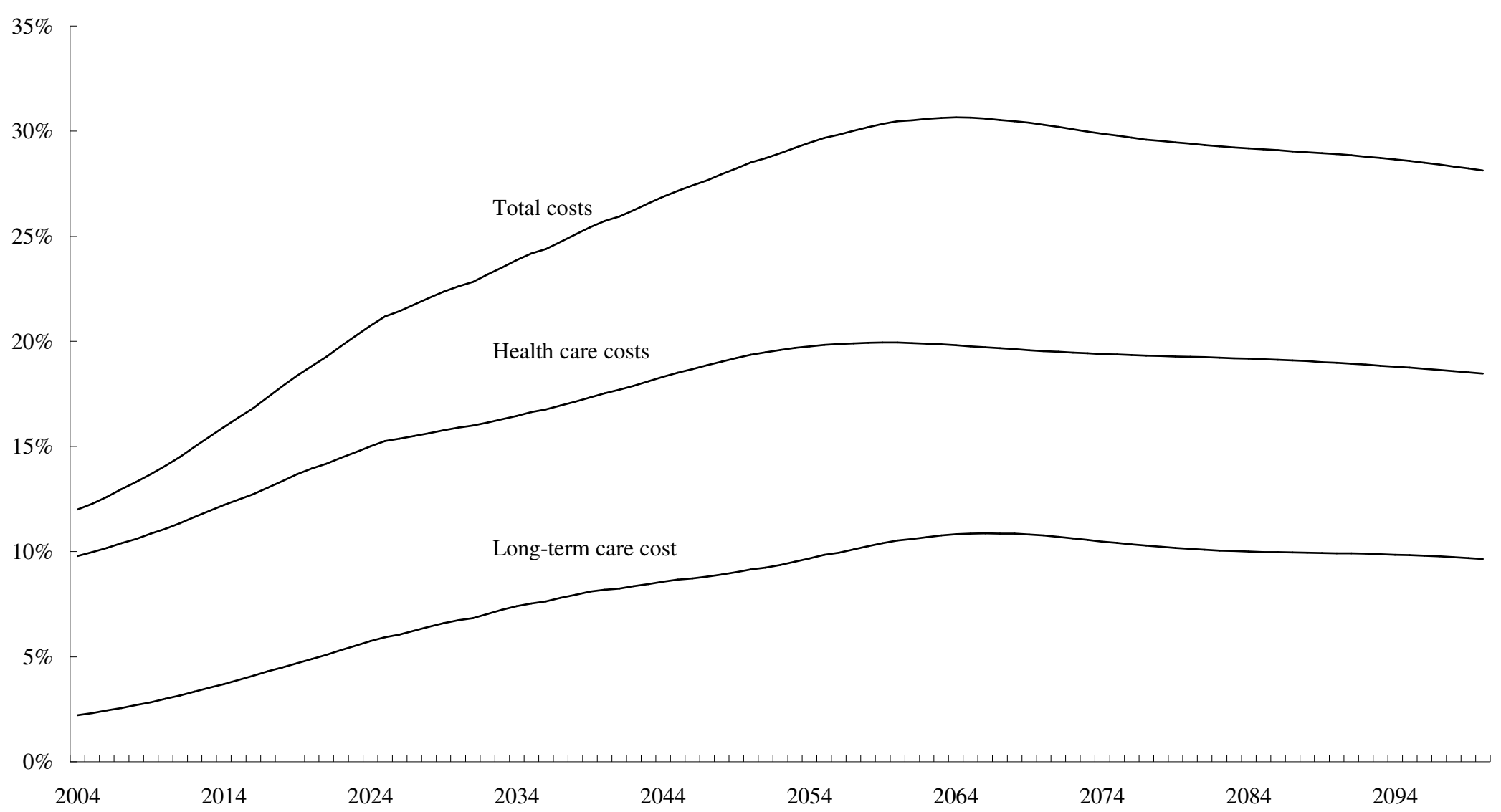


Figure 3: Lifetime Burden Rates by Generation under Policy A (Balanced Budget)

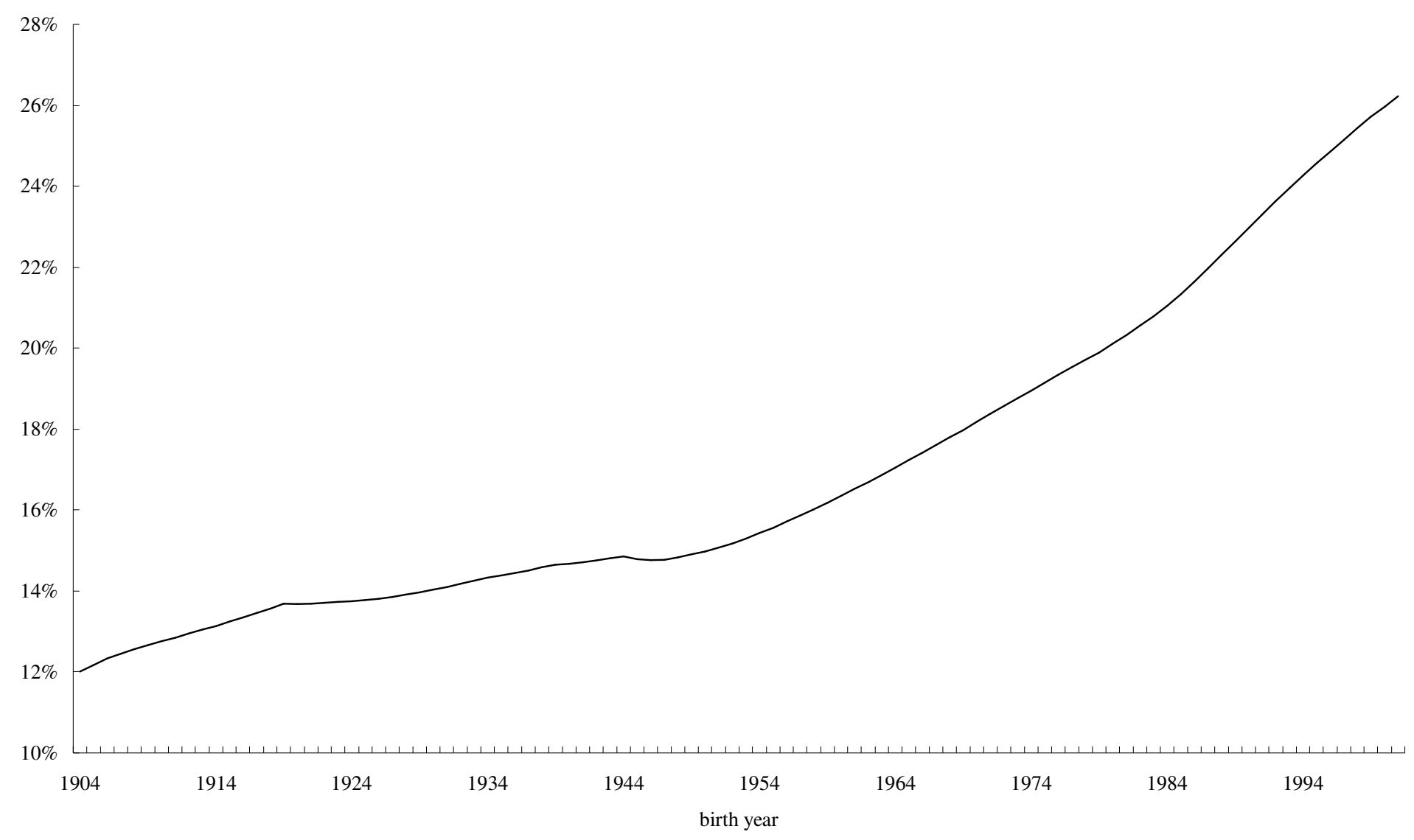

$-26-$ 


\subsection{Equalizing the burden by prefunding policies}

The increasing burden on future generations, as depicted in Figure 3, may be circumvented by implementing a policy that levies a constant burden rate over time. Such a policy aims at charging a high burden rate in advance so that sufficient funds can be accumulated in order to prepare for increasing costs in the future. Feldstein (1999) advocated the idea of prefunding Medicare, which is the US public health insurance for the elderly.

As an example of the prefunding of health and long-term care costs, we consider the following policy. With regard to health insurance, a portion of the prefunding would be channelized in order to finance the insurance payments dealing with health care costs with regard to the elderly (age 65 and over). Workers who are aged 15 and above make payments in the form of premiums. The health care costs for those aged 64 and below and government subsidies in the form of benefits to the elderly are financed by a pay-as-you-go system. Long-term care insurance employs a prefunding scheme, while government subsidies are financed by a pay-as-you-go system. Since the enrollees of the current system are those who are aged 40 and above, we assume that workers falling into this age group pay these premiums.

The setting of the interest rate is a key factor in determining the performance of a prefunding scheme. When we focus on the proportion of burdens to income, it is not the absolute levels but the difference between the interest rate and the wage growth rate that matters. The MHLW projection on public pension finance in May 2004 assumed that the nominal interest rate would be 3.2 percent and that the growth rate of nominal wage would be 2.1 percent. Our baseline case sets a 1 percentage point difference between the interest rate and the growth rate of wage. As an alternative scenario, the difference is set either as 0 percent or 2 percent. $^{12}$

12 Feldstein and Samwick's (1997) simulation of the prefunding of the US social security program assumed that the real rate of return is 9 percent, which is considerably higher as compared to ours. Their following researches (Feldstein and Samwick, 1998) used 5.5 percent as the rate of return, which is still higher as compared to ours. We employed lower interest rates due to the following reasons. Firstly, their rates of return are based on risky capital; however, we considered the risk-free rate of return. We think that the investment strategies pertaining to funded health care and long-term care insurance should be conservative because these insurances aim to finance a strictly targeted consumption item that cannot be easily substituted. Secondly, our simulation 
Since the current health and long-term care insurance program is set within a pay-as-you-go framework, a transition to a funded system should be designed. With regard to health care costs, we first calculate the contribution rate that is sufficient for the entire cohort born in FY 2001 to finance the expected value of their lifetime health insurance benefits beyond the age of 65 years. This rate is estimated to be 4.96 percent under the governmental projection and the baseline scenario of the interest rate. If the cohorts born after FY 2001 pay the premium at this rate, the total accumulated funds in FY 2100 would amount to 111.11 percent of the GDP. Hence, the transition process is designed in such a manner that it accumulates this level of funds with a constant premium rate until FY 2100. Since the current generations did not prefund their health care costs, 4.96 percent of the premium rate is not sufficient to meet the target in FY 2100. It is therefore concluded that a contribution rate of 8.52 percent will successfully accumulate the required funds.

The evolution of the funded system will be achieved in the following manner (Table 7 summarizes the numbers that represent the burdens under Policies A and B). When health care costs (excluding government subsidies) are financed by a pay-as-you-go scheme in FY 2004, the contribution rate with regard to the same for individuals aged 64 and below is 4.32 percent and for those aged 65 and above is 3.89 percent. When a transition toward a prefunding scheme begins in FY 2005, the contribution rate for the elderly increases to 8.52 percent under the governmental projection and maintains this value until FY 2100. Beyond FY 2100, the contribution rate for the elderly will shrink to 4.96 percent. As against this, the contribution rate for the health care costs of the aged below 64 is almost stable. It ranges between 3.97 percent and 4.3 percent.

process does not incorporate the general equilibrium effect, in which an accumulated social insurance fund tends to lower the interest rate of a large open economy. We therefore, attempt to infer the consequences of this effect by looking at a particular case where the interest rate is maintained at a low level from the beginning. Thirdly, given the recent poor performance of Japanese asset prices, a high rate of return does not appear plausible. 
Table 7: Contribution Rates under the Balanced Budget and Prefunding Schemes

\begin{tabular}{|c|c|c|c|c|}
\hline & \multirow[b]{2}{*}{2004} & \multirow{2}{*}{$\begin{array}{c}\text { (A) } \\
\text { Balanced budget } \\
2005-2100\end{array}$} & \multicolumn{2}{|c|}{$\begin{array}{c}(\mathrm{B}) \\
\text { Prefunding }\end{array}$} \\
\hline & & & $2005-2100$ & $2101-$ \\
\hline Total & 12.01 & $12.28-28.12$ & $19.62-26.70$ & \\
\hline \multicolumn{5}{|l|}{ Health insurance } \\
\hline Nonelderly & 4.32 & $3.97-4.30$ & & \\
\hline Elderly & 3.89 & $3.98-9.08$ & 8.52 & 4.96 \\
\hline Government subsidies & 2.69 & $2.84-10.07$ & & \\
\hline Long-term care insurance & 1.11 & $1.16-4.83$ & 3.95 & 2.17 \\
\hline
\end{tabular}

Note) Numbers represent the percentage of earnings ( 90 percent of compensation of employees and mixed income). The interest rate is based on the baseline case, and other parameters are based on the governmental projection.

The transition process of the long-term care insurance program is designed along lines parallel to the health insurance program. The contribution rate that is sufficient for the cohort born in FY 2001 to finance the expected value of their lifetime long-term care insurance benefits is 2.17 percent under the governmental projection. If the cohorts born after FY 2001 pay the premium at this rate, the total accumulated funds in FY 2100 would amount to 68.35 percent of the GDP. This amount of funds will be accumulated by a contribution rate of 3.95 percent during the transition process. When long-term care costs (excluding government subsidies) are financed by a pay-as-you-go scheme in FY 2004, the contribution rate is estimated to be 1.11 percent. When a transition toward a prefunding scheme begins in FY 2005, the contribution rate increases to 3.95 percent, and maintains this value until FY 2100. Beyond FY 2100, the contribution rate will shrink to 2.17 percent.

For the calibrated value in FY 2004, the health insurance payments for the nonelderly is estimated to be 4.32 percent of the total earnings and those for the elderly is estimated to be 3.89 percent of the total earnings, with the long-term care costs being estimated as 1.11 percent. When social insurance premiums and government subsidies are combined, the overall burden rate becomes 12.01 percent. Under the pay-as-you-go system, the social costs for the elderly will grow steadily. The total burden ratio will go up to 28.12 percent of the total earnings. The burden rate of health insurance payments 
will go up to 9.08 percent. The growth of government subsidies however, is more rapid, the highest level attained by it being 10.07 percent.

Under the prefunding scheme, it is estimated that the burden rate will increase from 12.01 percent in FY 2004 to 19.62 percent in FY 2005. The rate of change in total burdens at the initial point is 63 percent. Since government subsidies are bound to grow, as in the case of the pay-as-you-go system, the highest level attained by the total burden rate will be 26.70 percent in FY 2064.

Figure 4 compares the lifetime burden rates between the balanced budget and the prefunding schemes. We should note that the burden rates for those born after 2001 do not cover their whole lifetime because the simulation terminates in FY 2100. When the system is changed from a balanced budget to a prefunding one, generations who are born prior to 1997 will face a higher lifetime burden, and younger generations will benefit from a lower lifetime burden. The curve representing lifetime burden in Figure 4 becomes flatter. Hence, a prefunding scheme helps to reduce the inequality of burdens. This will be made possible only if the current generation agrees to share burdens with future generations.

Suzuki (2000) conducted a similar study dealing with the calculation of the transition to a fully-funded health insurance system. While our calculation unites the whole sector of health insurance, his calculation was based on the decomposition of the same into subsidiary systems of insurance. The transition was assumed to begin in FY 1995 and attain the state of a fully-funded scheme by FY 2100. With regard to the Society-managed Health Insurance for Employees (Kumiai Kenpo), the contribution rate is estimated to increase from 7.8 percent to 9.8 percent.

According to Suziki's specification, a fully-funded scheme finances an individual's lifetime health care costs. Before individuals begin to work, their pre-funding account has to borrow money. This account needs to borrow money during the early stages of an individual's life. The resulting number of aggregate funds would still be lower than the number involved in our scheme. This is primarily the reason why we reported a much larger hike in the contribution rate during the transition process as compared to that reported in Suzuki (2000). 
Figure 4: Lifetime Burden Rates under Policy A (Balanced Budget) and Policy B (Pre-funding)

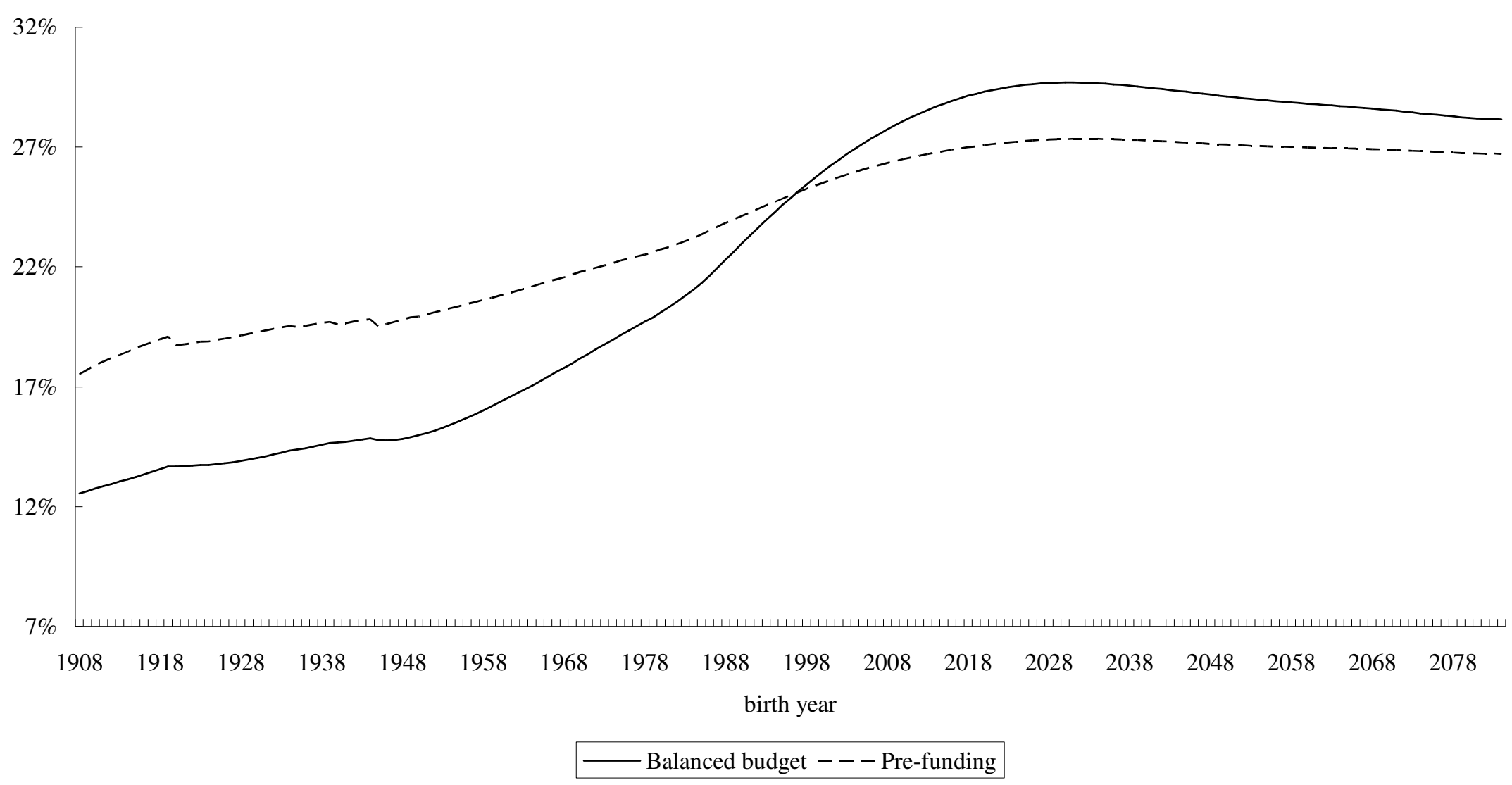




\subsection{Sensitivity Analysis}

Table 8 represents the contribution rates of the prefunding scheme in FY 2005-2100 and beyond FY 2100 under 27 diverse scenarios. The assumption of a labor force participation does not affect the contribution rate to a large extent. The difference in the health insurance contribution rate between a pessimistic scenario and the most optimistic scenario is 0.36 to 0.92 percentage points. The gap between the two is large, when the projection of social costs is pessimistic. This reflects the fact that a funding scheme is not influenced by a demographic change. On the other hand, the interest rate affects the contribution rate. Under the optimistic scenario (in which the interest rate is 2 percentage points higher than the wage growth rate), the contribution rate is 1.5 to 4.68 percentage points lower than that under the pessimistic scenario. The setting of social costs has an even larger impact on the contribution rate, as compared to the impact of interest rate on the same. The difference in the contribution rates during a transition period between a pessimistic scenario and an optimistic scenario is 3.13 to 6.33 percentage points.

The above findings can also be applied to the case of long-term care insurance. The effect of interest rate is relatively large as compared to the size of the benefits. The difference in the contribution rate between the optimistic and the pessimistic scenario ranges between 1.08 to 3.41 percentage points.

Even under the most optimistic scenario, the burden rate associated with health care and long-term care costs increases at a rate of 16.05 percentage points from the starting point. The rate of change in the total value of the burden rate is 34 percent, which is smaller than the governmental projection, but is still quite significant. Under the most pessimistic scenario, the rate of change is 85 percent. Although quantitative implications depend on the individual settings associated with each of the programs, a significant increase in the contribution rate is needed to implement a prefunding scheme. 
Table 8: Sensitivity Analysis of Contribution Rates in a Prefunding Social Insurance Scheme (Percent)

\begin{tabular}{|c|c|c|c|c|}
\hline & \multicolumn{2}{|c|}{ Health care for the elderly } & \multicolumn{2}{|c|}{ Long-term care } \\
\hline & $2005-2100$ & $2101-$ & $2005-2100$ & $2101-$ \\
\hline \multicolumn{5}{|c|}{$\begin{array}{l}\text { interest rate-growth rate }=2 \text { percent } \\
\text { social cost: optimistic }\end{array}$} \\
\hline \multirow{3}{*}{$\begin{aligned} \text { labor force: } & \text { very optimistic } \\
& \text { optimistic } \\
& \text { pessimistic }\end{aligned}$} & 6.25 & 2.74 & 2.66 & 1.08 \\
\hline & 6.36 & 2.81 & 2.71 & 1.10 \\
\hline & 6.61 & 2.90 & 2.82 & 1.14 \\
\hline \multicolumn{5}{|l|}{ social cost: pessimistic } \\
\hline \multirow{3}{*}{$\begin{aligned} \text { labor force: } & \text { very optimistic } \\
& \text { optimistic } \\
& \text { pessimistic }\end{aligned}$} & 7.56 & 3.45 & 3.31 & 1.38 \\
\hline & 7.69 & 3.53 & 3.37 & 1.41 \\
\hline & 7.99 & 3.64 & 3.51 & 1.46 \\
\hline \multicolumn{5}{|l|}{ social cost: very pessimistic } \\
\hline labor force: very optimistic & 9.38 & 6.06 & 4.47 & 2.81 \\
\hline optimistic & 9.55 & 6.20 & 4.55 & 2.88 \\
\hline pessimistic & 9.92 & 6.40 & 4.73 & 2.97 \\
\hline \multicolumn{5}{|c|}{$\begin{array}{l}\text { interest rate }- \text { growth rate }=1 \text { percent } \\
\text { social cost: optimistic }\end{array}$} \\
\hline labor force: very optimistic & 6.84 & 3.85 & 3.08 & 1.65 \\
\hline optimistic & 6.97 & 3.94 & 3.14 & 1.69 \\
\hline pessimistic & 7.26 & 4.08 & 3.27 & 1.75 \\
\hline \multicolumn{5}{|l|}{ social cost: pessimistic } \\
\hline \multirow{3}{*}{$\begin{aligned} \text { labor force: } & \text { very optimistic } \\
& \text { optimistic } \\
& \text { pessimistic }\end{aligned}$} & 8.36 & 4.84 & 3.88 & 2.12 \\
\hline & 8.52 & 4.96 & 3.95 & 2.17 \\
\hline & 8.88 & 5.14 & 4.12 & 2.25 \\
\hline \multicolumn{5}{|l|}{ social cost: very pessimistic } \\
\hline labor force: very optimistic & 11.09 & 8.58 & 5.69 & 4.35 \\
\hline optimistic & 11.30 & 8.78 & 5.80 & 4.46 \\
\hline pessimistic & 11.78 & 9.10 & 6.04 & 4.62 \\
\hline \multicolumn{5}{|l|}{$\begin{array}{l}\text { interest rate = growth rate } \\
\text { social cost: optimistic }\end{array}$} \\
\hline labor force: very optimistic & 7.75 & 5.36 & 3.74 & 2.51 \\
\hline optimistic & 7.91 & 5.48 & 3.81 & 2.57 \\
\hline pessimistic & 8.27 & 5.72 & 3.99 & 2.68 \\
\hline \multicolumn{5}{|l|}{ social cost: pessimistic } \\
\hline \multirow{3}{*}{$\begin{aligned} \text { labor force: } & \text { very optimistic } \\
& \text { optimistic } \\
& \text { pessimistic }\end{aligned}$} & 9.58 & 6.75 & 4.74 & 3.23 \\
\hline & 9.77 & 6.90 & 4.84 & 3.31 \\
\hline & 10.22 & 7.19 & 5.06 & 3.44 \\
\hline \multicolumn{5}{|l|}{ social cost: very pessimistic } \\
\hline \multirow{3}{*}{$\begin{aligned} \text { labor force: } & \text { very optimistic } \\
& \text { optimistic } \\
& \text { pessimistic }\end{aligned}$} & 13.68 & 12.05 & 7.62 & 6.71 \\
\hline & 13.96 & 12.33 & 7.78 & 6.86 \\
\hline & 14.60 & 12.84 & 8.14 & 7.15 \\
\hline
\end{tabular}

Note) Numbers represent the percentage of earnings ( 90 percent of compensation of employees and mixed income). In FY2004, the contribution rate of health insurance for the elderly is 3.89 percent and that for long-term care insurance is 1.11 percent. 
Figure 5 maps the total number of burden rates that are associated with the baseline scenario and six alternative scenarios which in turn take an alternative scenario with one variable among the three availables. Since the baseline scenario takes into account an intermediate assumption regarding the three variables, it takes the centermost line of all the seven lines. The line at the highest level represents the case of the most pessimistic social cost scenario. Since the growth of social costs is assumed to continue till the end of this century, the burden rate for future generations is far larger in this scenario as compared to that in other scenarios. The lowest line represents the case of the most optimistic social cost scenario. Social costs have the most significant impact on the burden rate. The impact of labor force on the burden rate is the least among the three variables considered so far. Higher interest rates can reduce the burden rates considerably. For the generation born in 2001, the lifetime burden rate is estimated to be 25.62 percent under the baseline scenario and 20.15 percent under the scenario with an interest rate higher by 1 percentage point. 
Figure 5: Total Burden Rates under Alternative Scenarios

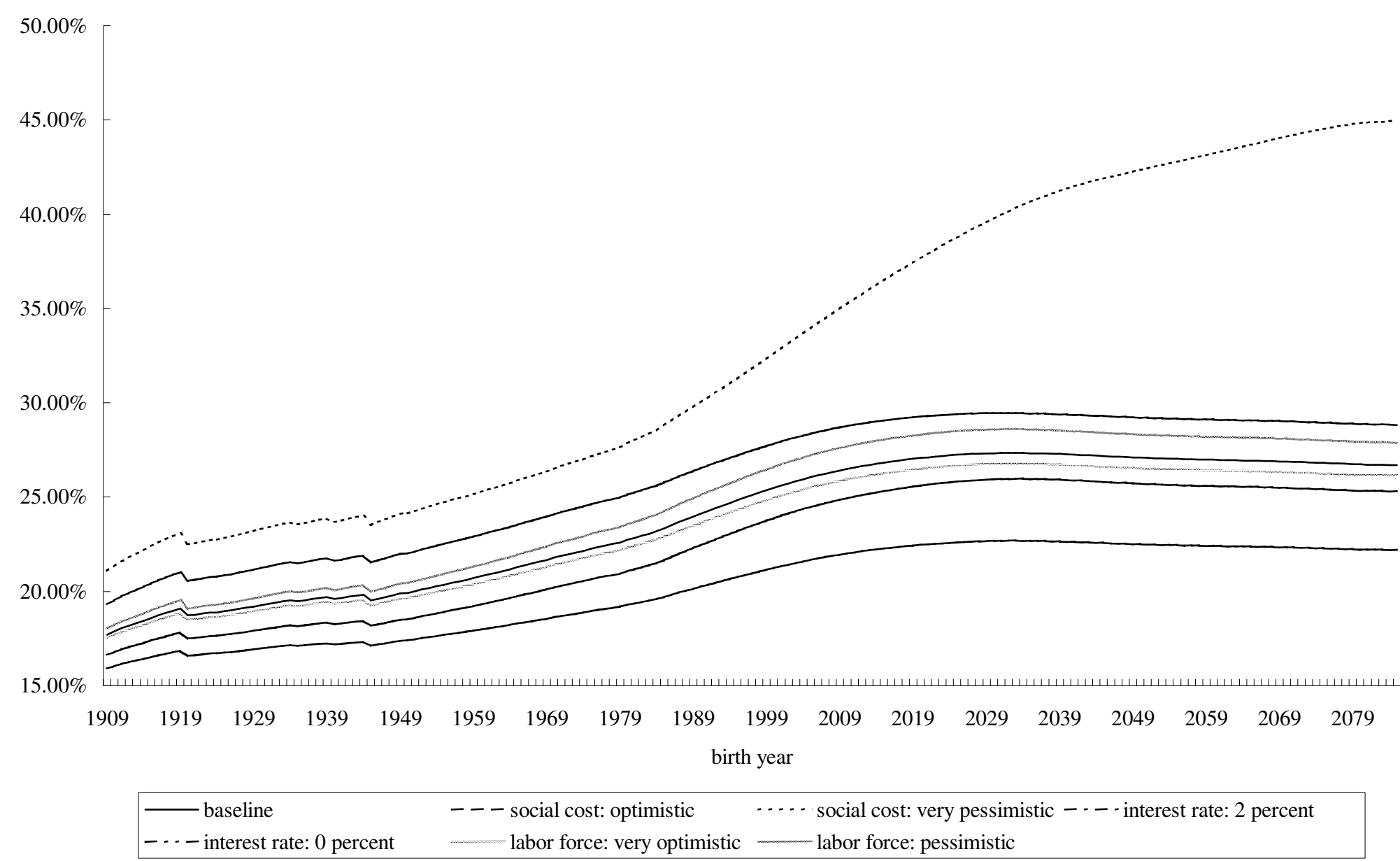




\section{Conclusion}

As the Japanese population structure changes, the current approach of financing (pay-as-you-go) the social costs will create a large increase in the magnitude of future burdens. It will also create an intergenerational inequity of burdens. We analyzed an alternative policy that prefunds the benefits for the elderly aged 65 and above. Prefunding is not very popular in Japan. Our analysis aims at providing real life scenarios with regard to this policy option and to stimulate policy discussions.

During the transition process until FY 2100, the scheme maintains a higher contribution rate in order to accumulate sufficient funds. With respect to the parameters implied by the governmental projection, the sum of the contribution rates with regard to health insurance and long-term care insurance increases from 5.00 percent of the total earnings to 12.47 percent of the same. The rate of increase in total burdens including taxes for subsidies is 63 percent.

Our sensitivity analysis has indicated that quantitative implications depend on the settings of the social costs, the labor force, and the interest rate. However, labor force scenarios do not have a considerable impact on the rate of burden. As against this, the setting of social costs has a significant impact. Although we cannot predict the exact amount of the necessary contribution rate that would be sufficient to transfer the funded system, it is certain that a significant increase in the contribution rate is inevitable. Even under the most optimistic scenario of the 27 possible scenarios, a necessary increase in the contribution rates of the two social insurances is 3.91 percentage points. The rate of increase in the total amount of burdens is 34 percent.

Implementing a prefunding social cost program may be a challenge because the initial increase in burdens is politically unfavorable. However, the cost of not introducing this scheme implies a heavier burden on future generations. Raising the contribution rate in an aggressive manner will help to reduce the intergenerational imbalance of burdens. 


\section{References}

Auerbach, Alan J., Jagadeesh Gokhale, and Laurence J. Kotlikoff (1991), “Generational Accounts: A Meaningful Alternative to Deficit Accounting," in David Bradford ed., Tax Policy and the Economy, Vol. 5, Cambridge, MA: MIT Press, pp. 55-110.

Bradford, David F., and Derrick A. Max (1997), "Implicit Budget Deficits: The Case of a mandated Shift to Community-Rated Health Insurance," in James M. Poterba ed., Tax Policy and the Economy, Vol. 11, Cambridge, MA: MIT Press, pp. $129-167$.

Culter, David M., and Louise Sheiner (2000), "Generational Aspects of Medicare," American Economic Review Papers and Proceedings, Vol. 90, No. 2, May, pp. 303-307.

Feldstein, Martin (1999), "Prefunding Medicare," American Economic Review Papers and Proceedings, Vol. 89, No. 2, May, pp. 222-227.

and Andrew Samwick (1997), "The Economics of Prefunding Social Security and Medicare Benefits," in Ben S. Bernanke and Julio Rotemberg eds., NBER Macroeconomics Annual 1997, Cambridge, MA: The MIT Press, pp. 115-148.

— Accounts," Tax Notes, Vol. 79, No. 5, May, pp. 615-620.

Iwamoto, Yasushi (1998), “Japan's Labor Force in the year 2020 (2020 Nen no Rodoryoku Jinko),' Keizai Kenkyu, Vol. 49, N0.4, October, pp. 297-307 (in Japanese).

— , Satoshi Takeshita, and Masashi Bessho (1997), "Public Health Insurance and Government Subsidies (Iryo Hoken Zaisei to Kohi Futan)," Financial Review, No.43, November, pp. 174-201 (in Japanese).

Maekawa, Satoko (2004), "Changes in Benefits and Burdens, by Generation, Arising from Social Security Reform (Shakai Hosho Kaikaku ni Yoru Sedaibetsu Jueki to Futan no Henka)," Financial Review, No. 72, August, pp. 5-19 (in Japanese).

Mitchell, Olivia S., John Pigott and Satoshi Shimizutani (2004), “Aged-Care Support in Japan: Perspectives and Challenges," NBER Working Paper No. 10882, November.

Niki, Ryu (1995), Medical Expenditure in Japan: From a Viewpoint of International 
Comparison (Nihon no Iryohi: Kokusai Hikaku no Kanten Kara), Tokyo: Igaku Syoin (in Japanese).

Nishimura, Syuzo (1997), "On the Possibility of Full-funded Social Health Insurance (Choki Tsumitategata Iryo Hoken Seido no Kanosei ni tsuite)," Iryo Keizai Kenkyu, Vol.4, December, pp.13-34 (in Japanese).

Ogura, Seiritsu (1994), “The Cost of Aging: Public Finance Perspectives for Japan,” in Noguchi, Yukio and David A. Wise eds., Aging in the United States and Japan, Chicago: The University of Chicago Press, pp.139-173.

—_ , and Takeshi Irifune (1990), "Waga Kuni no Jinko no Koreika to Kaku Koteki Iryo Hoken no Syushi ni tsuite," Financial Review, No. 17, August, pp.51-77 (in Japanese).

Ohkusa, Yasushi (2002), “Aging Effects on Medical Expenditure and Analysis for Duration of Hospitalization (Koreika no Iryohi heno Eikyo oyobi Nyuin Kikan no Bunseki)," Kikan Shakai Hosho Kenkyu, Vol. 38, No.1, June, pp.52-66 (in Japanese).

Shimizutani Satoshi and Haruko Noguchi (2004), "Economic Analysis of Long-term Care and Child Care Service Markets (Kaigo Hoiku Sabisu Shijo no Keizai Bunseki)," Tokyo: Toyo Keizai Shinposha (in Japanese).

Suzuki, Wataru (2000), “A Proposal for Removing Intergenerational Inequity from the Japanese Health Insurance System (Iryo Hoken ni okeru Sedaikan Fukohei to Tsumitatekin wo Motsu Fea na Zaisei Hosiki heno Iko)," Nihon Keizai Kenkyu, No. 40, March, pp. 88-104 (in Japanese).

(2002), “Analysis of Recent Increase of Demand for Long-term Care in Japan (Kaigo Sabisu Juyo Zoka no Yoin Bunseki)," Nihon Rodo Kenkyu Zasshi, No. 502, May, pp. 6-17 (in Japanese).

— Costs for the Elderly? (Jumyo no Chokika wa Rojin Iryohi Zoka no Youinka?)," Kokusai Kokyo Seisaku Kenkyu, Vol. 7, No. 2, March (in Japanese).

Tokita, Tadahiko et al. (1997), “The Present and Future National Medical Expenditure in Japan," Economic Analysis (Keizai Bunseki in Japanese), Vol. 152, September. 